\title{
Virtualization of Teaching and Learning of Engineering Students and its Impact on Self-Perception of Attitude Acquisition, in the Context of COVID-19
}

\author{
Omar Chamorro-Atalaya ${ }^{1}(\varpi)$, Soledad Olivares-Zegarra ${ }^{1}$, Nestor Alvarado-Bravo ${ }^{2}$, \\ Salvador Trujillo-Perez ${ }^{2}$, Almintor Torres-Quiroz ${ }^{2}$, Florcita Aldana-Trejo ${ }^{3}$, \\ Victor Villanueva-Acosta ${ }^{4}$ \\ ${ }^{1}$ National Technological University of Lima Sur, Lima, Peru \\ ${ }^{2}$ National University of Callao, Callao, Peru \\ ${ }^{3}$ Federico Villarreal National University, Lima, Peru \\ ${ }^{4}$ Autonomous University of Peru, Lima, Peru \\ ochamorroduntels.edu.pe
}

\begin{abstract}
This present describes the results of the evaluation regarding the self-perception of personal and social attitudes acquired by university students from an engineering faculty at a state university in Peru, in the context of virtual teaching and learning, declared by the health emergency by COVID-19; For which the following objectives were proposed, to determine the variation or impact that the self-perception of personal and social attitudes experienced, having as reference scenarios, the academic semester with face-to-face teaching (academic semester 2019B) and then the academic semester developed totally virtual (2020A). An exploratory-descriptive research level was used, with a longitudinal non-experimental design, whose population and sample is made up of 674 and 761 students, in the 2019B and 2020A semesters respectively. The data collection instruments were validated through Cronbach's Alpha, whose average results per academic semester were 0.960 and 0.958 . After the investigation, it was found that there is no negative impact, due to virtual teaching; On the contrary, on average, there was an increase in all levels of satisfaction, increasing the level very satisfied by $52.8 \%$ and the level satisfied by $3.25 \%$.
\end{abstract}

Keywords - Teaching, Learning Self-perception, Personal Attitudes, Virtualization

\section{Introduction}

Technological development and the speed of knowledge production in the present century constitute arguments that validate virtuality as a revolution within education [1]. Training through virtual teaching-learning environments is a necessary tool that today many university institutions put into practice in their development strategies and academic perspective [2]. However, it is a challenge for teachers to use these technological resources and adapt them as part of their pedagogical tools, which allow the development of the competences of university students $[3,4]$. 
An aspect to be highlighted is the importance of analyzing the self-perception of the personal and social attitude of the university student, to identify which aspects need to be improved, in such a way that they lead to a significant contribution, representing the university in the context social [5-7]. This is where the need to analyze the effects generated by virtual environments is highlighted, so that learning takes place, the consolidation of various competences and the personal construction of knowledge from values and experiences [8,9].

One aspect to take into account is the development of personal and social skills and attitudes in engineering careers, through virtual environments; since many of these careers in their face-to-face mode make use of or interact with equipment and instruments [10]. Engineering education since its inception has been conditioned by different changes that have made it evolve and at the same time enrich itself [11]. Therefore, the training of an engineer in accordance with the needs of the environment in which he lives and develops and the way in which he must face it is a concern of all times [12].

Now if these issues are exposed, we take you to the context of the sanitary emergency declared by the COVID-19 pandemic; To combat this pandemic that has caused damage at a global level in all sociocultural and economic scenarios, different measures have been applied according to the context of each country, with the intention of counteracting the effects of this disease and minimizing the damage that they produce [13]. These dispositions have led to a transformation in life styles and behaviors in general, in an attempt to maintain daily life, but from a virtual environment $[14,15]$.

In this sense, this article aims to describe the results of the evaluation regarding the self-perception of personal and social attitudes acquired by university students of professional engineering schools, from the virtualization of the teaching and learning process, in the context of the health emergency due to COVID-19; for which the following objectives have been defined.

\section{Research methodology}

\subsection{Research level and design}

The research level is exploratory-descriptive; it is exploratory since initially it is unknown how the self-perception of personal and social attitudes was affected, as part of the context of the health emergency, which led to the realization of totally virtual classes. It is descriptive because it is intended to use statistical indicators in order to assess the level of impact experienced by each of the indicators that make up the variable under analysis. This analysis is intended to represent a frame of reference that contributes to university managers to take actions in relation to how to quantitatively improve the value of self-perception of personal and social attitudes. The research design is non-experimental of a longitudinal type, because the population is analyzed and studied in its normal or natural state, without applying any action or improvement plan to the elements that make up the unit of analysis; It should be noted that it is defined longitudinal because the data are collected in 
different academic periods or semesters; the same thing that makes the sample different.

\subsection{Population and sample}

The population is made up of students of professional engineering careers; Being precise, the population of the academic semester 2019B (totally face-to-face teaching and learning) is made up of 674 students, while the population corresponding to the academic semester 2020A (total virtualization of teaching and learning) is made up of 761 students. Data collection was obtained from the application of a virtual satisfaction survey, carried out on a mandatory basis to all students in the two contexts defined in the previous paragraph; in this sense, the sample is made up of the entire population.

\subsection{Data collection technique}

The technique used in this research is the survey technique; the same that is part of the data collection instrument approved by the senior management of the university in analysis. Thus, the reliability of the data collected for each of the indicators corresponding to the variable under analysis by academic semester was validated through Cronbach's alpha, using the statistical software SPSS version 25; obtaining that the value of Cronbach's alpha in the academic semester 2019B and 2020A, turned out to be 0.960 and 0.958 respectively. Table 1 shows the indicators that make up the data collection instrument, as well as the coding assigned to each of them.

Table 1. Indicators that make up the data collection instrument

\begin{tabular}{|c|l|}
\hline $\begin{array}{c}\text { Coding assigned to each } \\
\text { indicator }\end{array}$ & \multicolumn{1}{c|}{ Indicator in analysis } \\
\hline I1 & With the commitment to undertake studies with responsibility \\
\hline I2 & With the commitment to represent the university \\
\hline I3 & With the respect that you show by teachers and authorities \\
\hline I4 & With the respect that you treat your classmates \\
\hline I5 & With the commitment to be better every day \\
\hline I6 & With the commitment to society and the environment \\
\hline
\end{tabular}

It should be noted that self-perception of satisfaction was measured using the Likert scale, with 1 being the coding for the dissatisfied level, 2 for the not very satisfied level, 3 for the level and 4 for the very satisfied level. 


\section{Results and Discussion}

\subsection{Results of the investigation}

Figure 1 shows the results of the self-perception of developing personal and social attitudes grouped by level of satisfaction, comparing them in the scenarios of total virtualization (2020A) and total presence (2019B), of the teaching-learning process; In this sense, it is observed that in all the indicators, on average, there was no decrease in self-perception (if we group the levels satisfied and very satisfied), nor a significant increase (if we group the levels dissatisfied and not very satisfied).

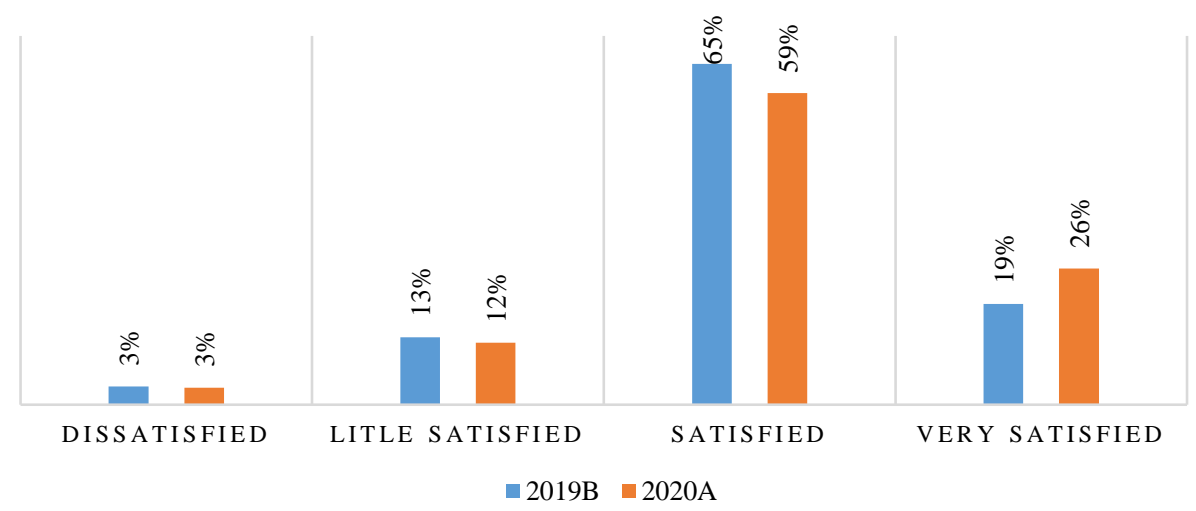

Fig.1. . Comparison of average results by level of satisfaction by academic semester

Although it is true a priori it could be thought that the virtualization of the teaching-learning process in the context of the state of emergency declared in Peru, due to the COVID-19 pandemic, would be negative, by abruptly passing from the face-to-face to the virtual, on the contrary, it allowed to achieve an average stability of the indicators of the self-perception of personal and social attitudes in engineering university students.

Thus, figure 2 shows the detail for each indicator; And it is that if it had to be answered, which indicator should be taken into account in order to improve the selfperception of the variable under analysis, in this context of the virtuality of the teaching-learning process, it would have to be divided into two questions, which indicator Satisfied level decreased in the context of virtualization? And which indicator of the level of dissatisfaction decreased significantly in the context of virtualization?

Regarding the first question, we could point out that indicator I1 (With the commitment to undertake studies with responsibility), decreased by $7 \%$; being the indicator that experienced a greater level of decrease in self-perception. Regarding the second question, we could point out that there is no indicator that experienced an increase in self-perception dissatisfaction. 


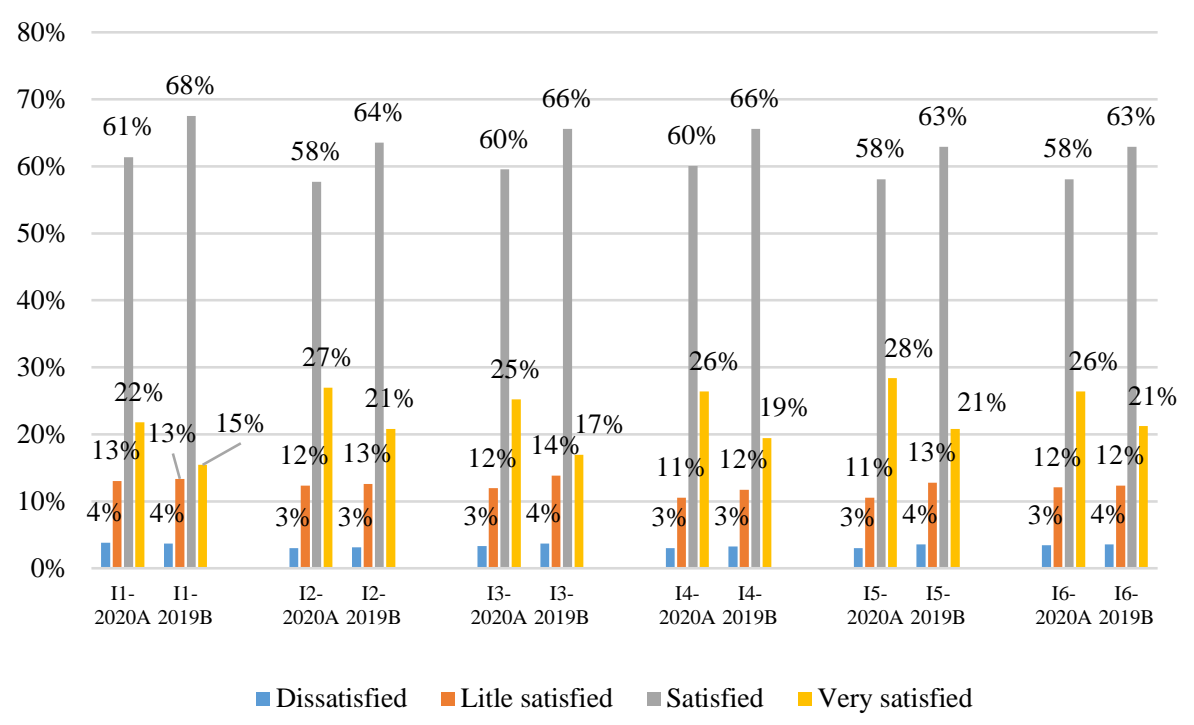

Fig.2. Comparison of satisfaction levels for each indicator by academic semester

In that sense, taking into account the indicator that experienced a greater level of decrease in terms of the very satisfied level (I1), I will carry out an analysis of crossed tables or contingency tables, in order to establish the level of interaction or association with respect to the other indicators under analysis.

Table 2 shows that there is a level of interaction between indicator I1 and indicator I2; since in the analysis of the crossed tables, it is shown that $68.8 \%$ of the $21.8 \%$ of surveyed students indicate that they are very satisfied with the development of indicator I1, as well as indicator I2.

Table 2. Result of the cross table analysis between indicator I1 and I2

\begin{tabular}{|c|c|c|c|c|c|c|}
\hline & & \multicolumn{4}{|c|}{ I2 } & \multirow{2}{*}{ Total } \\
\hline & & 1 & 2 & 3 & 4 & \\
\hline \multirow{4}{*}{ II } & 1 & $82,6 \%$ & $6,4 \%$ & $0,7 \%$ & $0,5 \%$ & $3,8 \%$ \\
\hline & 2 & $13,0 \%$ & $71,3 \%$ & $6,4 \%$ & $0,5 \%$ & $13,0 \%$ \\
\hline & 3 & & $20,2 \%$ & $87,9 \%$ & $30,2 \%$ & $61,4 \%$ \\
\hline & 4 & $4,3 \%$ & $2,1 \%$ & $5,0 \%$ & $68,8 \%$ & $21,8 \%$ \\
\hline \multicolumn{2}{|c|}{ Total } & $100,0 \%$ & $100,0 \%$ & $100,0 \%$ & $100,0 \%$ & $100,0 \%$ \\
\hline
\end{tabular}

Table 3 shows that $73.4 \%$ of the $21.8 \%$ of surveyed students indicate that they are very satisfied with the self-perception of the development of indicator I1 and indicator I3; This result makes it possible to establish that there is a significant level of interaction between the two indicators. 
Table 3. Result of the cross-table analysis between indicator I1 and I3

\begin{tabular}{|c|c|c|c|c|c|c|}
\hline & & \multicolumn{4}{|c|}{ I3 } & \multirow{2}{*}{ Total } \\
\hline & & 1 & 2 & 3 & 4 & \\
\hline \multirow{4}{*}{ II } & 1 & $80,0 \%$ & $8,8 \%$ & $0,2 \%$ & & $3,8 \%$ \\
\hline & 2 & $12,0 \%$ & $60,4 \%$ & $8,4 \%$ & $1,6 \%$ & $13,0 \%$ \\
\hline & 3 & & $29,7 \%$ & $86,5 \%$ & $25,0 \%$ & $61,4 \%$ \\
\hline & 4 & $8,0 \%$ & $1,1 \%$ & $4,9 \%$ & $73,4 \%$ & $21,8 \%$ \\
\hline \multicolumn{2}{|c|}{ Total } & $100,0 \%$ & $100,0 \%$ & $100,0 \%$ & $100,0 \%$ & $100,0 \%$ \\
\hline
\end{tabular}

In this third case of analysis between indicators I1 and I4, it is shown in table 4 that $72.6 \%$ of the $21.8 \%$ of students surveyed indicate that they are very satisfied with the self-perception of the development of indicator I1 and of indicator I3; This result makes it possible to establish that there is a significant level of interaction between the two indicators.

Table 4. Result of the cross-table analysis between indicator I1 and I4

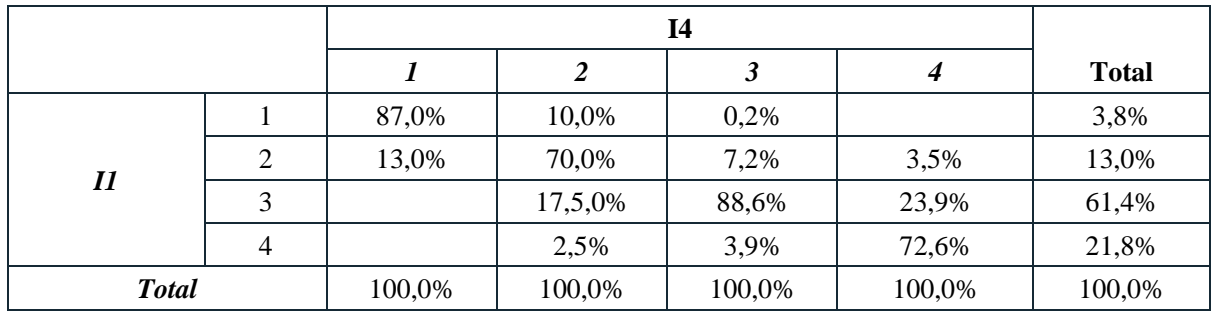

Table 5 shows that $69.9 \%$ of the $21.8 \%$ of surveyed students indicate that they are very satisfied with the self-perception of the development of indicator I1 and indicator I5; This result makes it possible to establish that there is a significant level of interaction between the two indicators.

Table 5. Result of the cross-table analysis between indicator I1 and I5

\begin{tabular}{|c|c|c|c|c|c|c|}
\hline & & \multicolumn{4}{|c|}{ I5 } & \multirow[b]{2}{*}{ Total } \\
\hline & & 1 & 2 & 3 & 4 & \\
\hline \multirow{4}{*}{ I1 } & 1 & $91,3 \%$ & $5,0 \%$ & $0,9 \%$ & & $3,8 \%$ \\
\hline & 2 & $8,7 \%$ & $75,0 \%$ & $7,0 \%$ & $2,8 \%$ & $13,0 \%$ \\
\hline & 3 & & $20,0 \%$ & $88,7 \%$ & $27,3 \%$ & $61,4 \%$ \\
\hline & 4 & & & $3,4 \%$ & $69,9 \%$ & $21,8 \%$ \\
\hline \multicolumn{2}{|c|}{ Total } & $100,0 \%$ & $100,0 \%$ & $100,0 \%$ & $100,0 \%$ & $100,0 \%$ \\
\hline
\end{tabular}

\subsection{Discussion}

The fact that university academic activities are developed virtually, due to the declaration of the state of health emergency in Peru, did not significantly effect on 
average the levels of self-perception of acquiring or developing personal and social attitudes, in students of professional engineering schools. On the contrary, it is seen that the students adapted quickly to the context of the virtualization of academic activities, that on the one hand; On the other hand, it is necessary that the teachers and authorities collaborated in that despite this untimely change from working minimally with tools for the virtualization of the teaching-learning process to going to fully virtualize all academic activities, they knew how to maintain a pedagogy in accordance with the circumstances that made it possible to guarantee and maintain the level of self-perception of the variable under analysis. The results indicate us in a concrete way that the increase in developing personal or social attitudes was not affected, even more so it was achieved that the average level of dissatisfaction went from $17.06 \%$ to $16.82 \%$. In this regard, in [16] it is pointed out that, it was discovered that personal factors from the virtualization of the teaching-learning process do not experience any direct impact with respect to their satisfaction; This aspect will corroborate the results obtained in this research since it was evidenced that there was no negative effect in relation to the variable under analysis. Likewise, the results obtained by Elnadi [17] and Mirahmadizadeh [18] support the findings obtained in this research.

In relation to the indicator that showed a greater negative impact in relation to the self-perception of the virtualization of the teaching-learning process, it was the indicator I1 (With the commitment to undertake studies with responsibility), which decreased in the level of "satisfaction" of the self-perception rating scale, 7\%; In this regard, it can be pointed out that this level is not significant, if the very satisfied level is also taken into account, since if the two levels determine the degree of satisfaction in this indicator, it will be determined that there was no significant negative effect; Now this indicator is linked to the context in which the teaching-learning process takes place, since it was a new scenario, to a certain point unique, the one experienced by the students; All so, what is relevant is that it was evidenced under this first experience, that the tools of virtulization allow to guarantee a teaching-learning process according to these times. In [19], it is stated that the level of self-perception regarding attitudes had high values in the context of COVID-19, however it had a $17.2 \%$ drop, with respect to the previous year; It is inferred that much is due to the pandemic scenario; but an aspect to highlight is the professional career in analysis, while the author of the quote, analyzes students from another career, in my case the research is carried out on students of mechanical engineering, electronics, systems and environmental engineering; professional careers in which simulation software and technological tools allow the student to build their knowledge congruent with the competencies defined in the curricular plans, different from other careers, for example those in measurement, which is not only enough with the use of simulators. The result obtained in this investigation is also validated through the investigation carried out by Hatabu [20].

\section{Conclusions}

It is concluded that the virtualization of the teaching-learning process does not significantly affect the self-perception of the acquisition of personal and social 
attitudes; this frame of reference will serve to generate policies for the frequent use of technological tools that allow the continuity of the teaching-learning process.

It is concluded that of the six indicators under analysis, only an effect is seen in the level of evaluation of the self-perception "satisfied", in the other cases, there is no decrease, however when associating them with the level very satisfied, it is perceived that there is no negative effect due to the virtualization of the teaching-learning process. This aspect should lead us to reflect on the importance of consolidating the use of technological platforms and tools, not only in this context of a pandemic, but in future scenarios, making their use sustained by engineering students, who were the ones to whom the data collection instrument.

\section{$5 \quad$ References}

[1] Ran, J., Hou, K., Li, K. (2018). A High Security Distance Educaction Platform Insfraestructure Based on Private Cloud, International Journal of Emerging Technologies in Learning, 13 (10): 42-54. https://doi.org/10.3991/ijet.v13i10.9450

[2] Huang, J., Shen, G., Ren, X. (2021). Conotation Analysis and Paradigm Shift of Teaching Design under Artificial Intelligence Technology, International Journal of Emerging Technologies in Learning, 16 (5): 73-86. https://doi.org/10.3991/ijet.v16i05.20287

[3] Razzaq, A. Tri, Y. (2018). Smartphone Habits and Behaviors in Suppoting Students SelftEfficacy, International Journal of Emerging Technologies in Learning, 13 (2): 94-109. https://doi.org/10.3991/ijet.v13i02.7685

[4] Espino-Román, P., Olaguez-Torres, E., Davizon-Castillo, Y. (2015). Analysis of the perception of the environment of Mechatronics Engineering Students, University Training Journal, 8(4): 45-54.

[5] Tobón, M., Durán, M. Añez, A. (2017). Academic and Professional Satisfaction of University Students, Electronic Journal of Humanities, Education and Social Communication, 22 (11): 110-129.

[6] Escribano, E. (2018). Teacher performance as a factor associated with educational quality in Latin America, Education Journal, 42 (2): 49-58. https://doi.org/10.15517/revedu . $\mathrm{v} 42 \mathrm{i} 2.27033$

[7] Olaguez-Torres, E., Espino-Román, P., Acosta-Pérez, C., Mendez-Barcelo, A. (2019). Action plan based on the perception of students of the Polytechnic University of Sinaloa regarding Solid Waste Recycling and Environmental Education, University Training Journal, 12(3): 3-14. https://dx.doi.org/10.4067/S0718-50062019000300003

[8] Anaya, T., (2020). Perception of Organizational Commitment in Students of a Lima Art School, Journal of Research in Psychology, 23(1): 145-158. http://dx.doi.org/10.15381 /rinvp.v23i1.18098

[9] Castañuela, B. (2016). The University and its Social Function, CienciAcierta Journal, 1(2): 1-14.

[10] Williner, B. (2021). The class invested through homework: An experience during the period of isolation by Covid-19 in Engineering Careers, Iberoamerican Journal of Technologies in Education and Education in Technologies, 28: 48-55. https://doi.org/ $\underline{10.24215 / 18509959.28 . e 6}$

[11] Neri, J., Hernández, C. (2019). Young engineering university students and their perception of soft skills, Iberoamerican Journal for Research and Development of Education, 9(18): 124. https://doi.org /10.23913/ride.v9i18.445 
[12] Capote, G., Rizo, N., Bravo, G. (2016). Engineering Education Today: A Necessary Explanation, Scientific Journal of the University of Cienfuegos, 8(1): 21-28.

[13] Vialart, M. (2020). Didactic strategies for the virtualization of the teaching-learning process in times of COVID-19, Higher Medical Education Journal, 34(3): 298-308.

[14] Cayo-Rojas, C., Agramonte-Rosell, R. (2020). Challenges of Virtual Education in Dentistry in times of the COVID-19, Cuban Journal of Stomatology, 57(3), 54-62.

[15] Ojeda-Beltran, A., Ortega-Alvarez, D., Boom-Carcamo, E. (2020). Analysis of the perception of face-to-face students about virtual classes in response to the COVID-19 crisis, Espacios Journal, 41 (42): 81-86. https://doi.org/10.48082/espacios-a20v41n42p07

[16] Chen, T., Peng, L., Yin, X. Rong, X. Yang, J., Cong, G. (2020). Analysis of User Satisfaction with Online Education Platforms in China during the COVID-19 Pandemic, Halthcare, 8: 200-226. https://doi.org/10.3390/healthcare8030200

[17] Elnadi H., Odetokun, I., Bolarinwa, O., Ahmed, Z. (2021). Knowledge, attitude, and perceptions towards the 2019 Coronavirus Pandemic: A bi-national survey in Africa. Journal Plos One, 6(2): e0247351. https://doi.org/10.1371/journal.pone.0247351

[18] Mirahmadizadeh, A., Ranjbar, K., Shahriarirad, R. (2020). Evaluation of students' attitude and emotions towards the sudden closure of schools during the COVID-19 pandemic: a cross-sectional study. BMC Psychol 8 (1), 134-143. https://doi.org/10.1186/s40359-020$\underline{00500-7}$

[19] Angelo, A., Alemayehu, D., Dacho A. (2020). Knowledge, attitudes, and practices toward Covid-19 and Associated Factors among University Students in Mizan Tepi University, 2(14): 349-360. https://doi.org/10.2147/idr.s299576

[20] Hatabu, A., Mao, X., Zhou, Y., Kawashita, N. (2020). Knowledge, attitudes, and practices toward Covid-19 among university students in Japan and associated factors: An online cross-sectional survey. Journal Plos One, 15(12): e0244350. https://doi.org/10.1371 /journal.pone. 0244350

\section{Authors}

Omar Freddy Chamorro Atalaya and Soledad del Rosario Olivares Zegarra, Teachers at the National Technological University of Lima Sur, Lima, Peru.

Nestor Marcial Alvarado Bravo, Salvador Apolinar Trujillo Perez and Almintor Giovanni Torrez Quiroz, Teachers at the National University of Callao, Callao, Peru.

Florcita Aldana Trejo, Teacher at the Federico Villarreal National University, Lima, Peru.

Victor Villanueva Acosta, Principal Professor of the Autonomous University of Peru, of the Faculty of Human Sciences and Professional School of Psychology.

Article submitted 2021-04-12. Resubmitted 2021-05-27. Final acceptance 2021-05-28. Final version published as submitted by the authors. 